\title{
Role of 5-hydroxytryptamine in intestinal water and electrolyte movement during gut anaphylaxis
}

\author{
F H Mourad, L J D O’Donnell, E Ogutu, J A Dias, M J G Farthing
}

\begin{abstract}
Exposure of sensitised intestine to specific allergen is known to produce appreciable reduction in water and electrolyte absorption. The mediators participating in this process have not been fully characterised. The effects of the 5-hydroxytryptamine $\left(5-\mathrm{HT}_{2}\right)$ and $5-\mathrm{HT}_{3}$ receptor antagonists, ketanserin and granisetron, respectively, on water movement during intestinal anaphylaxis were studied. Hooded Lister rats (120-150 g) were sensitised to ovalbumen and 14 days later, intestinal water and electrolyte movement was assessed at $\mathbf{1 0}$ minute intervals by in situ jejunal perfusion with a plasma electrolyte solution (PES) or PES containing $20 \mathrm{mg} / \mathrm{l}$ ovalbumen. Within 20 minutes of exposure to PES+ovalbumen, net water secretion that could be completely prevented by the mast cell stabilising agent doxantrazole occurred compared with absorption with PES alone (median $-20 \mu \mathrm{l} / \mathrm{min} / \mathrm{g}$ (interquartile range -43 to -5 ), $n=11$ ), $v$ (107 (86 to 113), $n=10 ; p<0 \cdot 01$ ). Pre-treatment with subcutaneous ketanserin 200 $\mu \mathrm{g} / \mathrm{kg}(\mathbf{n}=7)$ or granisetron $300 \mu \mathrm{g} / \mathrm{kg}(\mathrm{n}=8)$ partially inhibited the secretory response to PES +ovalbumen (18 (11 to 48) and 13 (6 to 32$)$ respectively; both $p<0.01$ compared with PES +ovalbumen control). After 40 minutes perfusion with PES + ovalbumen, the changes in water movement were less pronounced 24 ( -3 to 43$)$ and neither ketanserin or granisetron had any effect (ketanserin: 48 (28 to 87), granisetron: 41 (32 to 83); NS). In all experiments, sodium and chloride movement paralleled that of water. Thus, the profound water secretion that occurs in the early stages of intestinal anaphylaxis is partly 5-HT dependent because it can be reversed by $5-\mathrm{HT}_{2}$ and 5-HT 3 receptor antagonists. Other mediators must also be involved, especially in the late phase of anaphylaxis. (Gut 1995; 36: 553-557)
\end{abstract}

Department of Gastroenterology, St Bartholomew's Hospital, London

F H Mourad

L J D O'Donnell

E Ogutu

J A Dias

M J G Farthing

Correspondence to: Professor M Farthing,

Department of

Department of

St Bartholomew's Hospital,

London EC1A 7BE.

Accepted for publication

8 August 1994
Keywords: 5-hydroxytryptamine, gut anaphylaxis, intestinal perfusion, food allergy.

IgE mediated food allergy is estimated to affect $2-5 \%$ of the general population and up to $27 \%$ of children, ${ }^{1}$ most of whom report gastrointestinal symptoms including diarrhoea, abdominal pain, nausea, and vomiting. ${ }^{23}$ Studies in animal models of food allergy have shown that exposure of a previously sensitised intestinal mucosa to a specific allergen leads to mast cell degranulation ${ }^{4}$ and a considerable decrease in water and electrolyte absorption, ${ }^{5}$ so called intestinal anaphylaxis. The changes in water and electrolyte movement probably contribute to the symptoms of IgE mediated food allergy in humans. The mediators participating in this process, however, have not been fully characterised. 5-Hydroxytryptamine (5-HT) may be an important mediator in intestinal anaphylaxis for several reasons. 5-HT is present in mast cells and enteric neurons, and is known to be a potent intestinal secretagogue. ${ }^{6}$ In vitro studies using sensitised rat intestinal segments mounted in Ussing chambers have shown that $5-\mathrm{HT}_{2}$ receptor antagonists can decrease $^{7}$ or completely abolish ${ }^{8}$ antigen induced changes in short circuit current. Similarly, Baird et al ${ }^{9}$ have shown in vitro the importance of $5-\mathrm{HT}_{3}$ receptors and enteric neurons in type 1 hypersensitivity reaction in guinea pig intestinal segments. However, in vivo studies of the effect of 5-HT receptor antagonists on water and electrolyte movement during intestinal anaphylaxis have not been reported.

The aim of our study was to assess in vivo the importance of 5-HT as a mediator of the physiological events occurring during IgE intestinal anaphylaxis by examining whether $5-\mathrm{HT}_{2}$ and 5-HT 3 receptor antagonists, ketanserin and granisetron respectively, can modulate the changes in water and electrolyte movement in an animal model of gut anaphylaxis.

\section{Methods}

\section{Animal model}

Male Hooded Lister rats (120-150 g body weight) were inoculated intraperitoneally with $10 \mu \mathrm{g}$ ovalbumen with alum adjuvant as previously described. ${ }^{10}$ Fourteen days later, serum anti-ovalbumen IgE was measured by passive cutaneous anaphylaxis. ${ }^{5}$ Briefly, multiple dilutions $(1: 2$ to $1: 16)$ of serum $(0 \cdot 1 \mathrm{ml})$ were injected intradermally on the shaved back of male Wistar rats. Forty eight hours later, animals were given an intracardiac injection of $2.5 \mathrm{mg}$ egg albumen in $0.5 \mathrm{ml}$ of $1 \%$ Evans blue and skin reactions were read after 30 minutes. Titres were recorded as the greatest dilution of serum producing a colour reaction measuring $5 \mathrm{~mm}$ or more in diameter.

\section{Intestinal perfusion}

On day 14 and after 18 hours fast with free access to water, sensitised rats were anaesthetised with intraperitoneal injection of sodium pentobarbitone $(60 \mathrm{mg} / \mathrm{kg})$ and maintained throughout the experiment by 

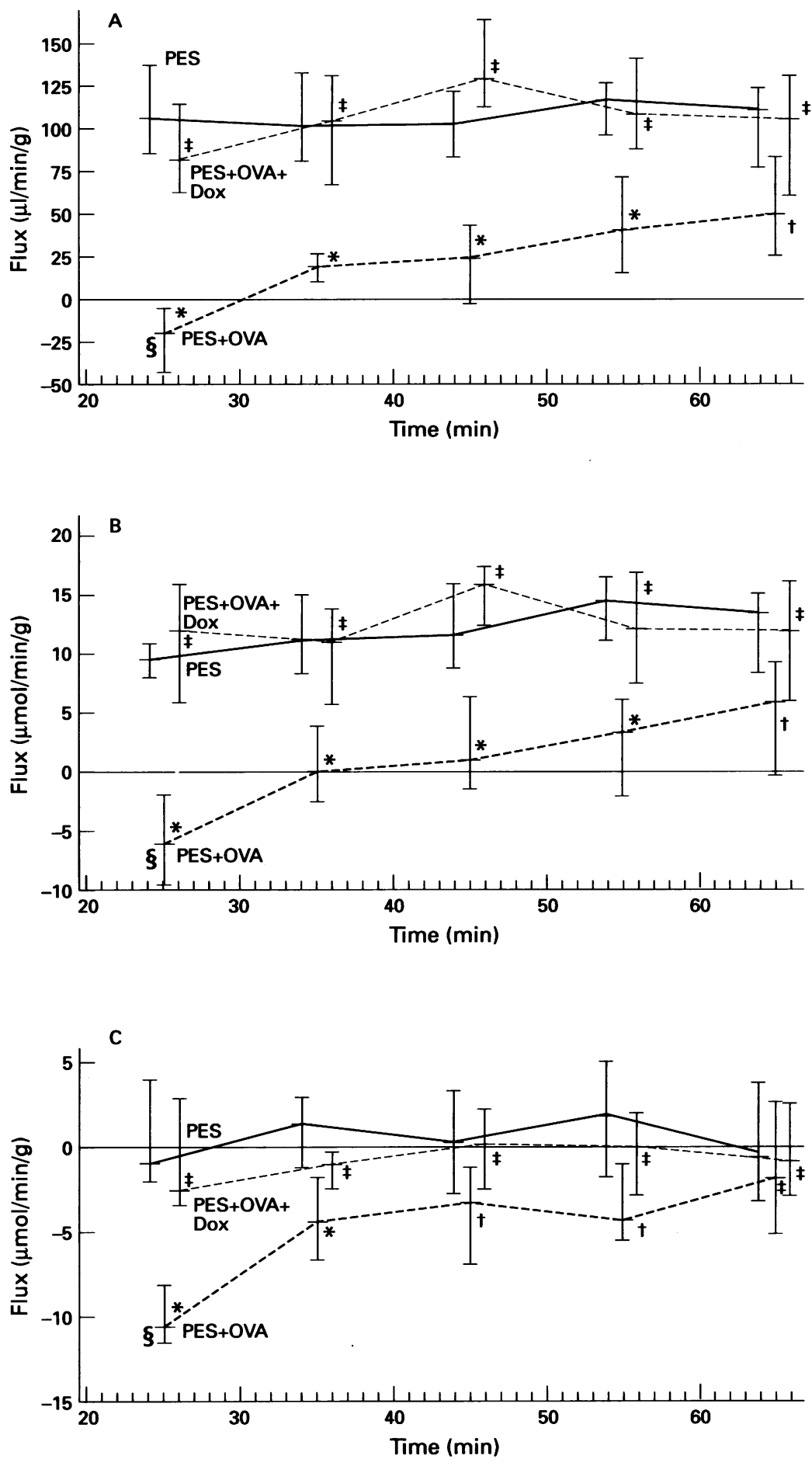

Figure 1: Water (A), sodium (B), and chloride (C) movement in control (PES, $n=10)$ and in challenged rats during gut anaphylaxis (PES +ovalbumen, $n=11$ ) and the effect of doxantrazole (PES +OVA+Dox, $n=8)$. Time (min): time after the start of perfusion; $P E S$ plasma electrolyte solution, OVA: ovalbumen. ${ }^{\star} p<0 \cdot 01,+p<0 \cdot 05, \neq N S$ compared with PES. $\$ p<0.05$ compared with 30-40 minute time period. I median, IQR.

interval intraperitoneal injections (15-30 $\mathrm{mg} / \mathrm{kg}$ ) as necessary. The abdomen was opened through a midline incision and a $15 \mathrm{~cm}$ segment of jejunum, starting $5 \mathrm{~cm}$ distal to the ligament of Treitz, was cannulated at proximal and distal ends. The isolated intestinal segment was gently flushed with warm isotonic saline and the intestine returned to the abdominal cavity and the abdomen closed. The intestinal segment was then perfused at a rate of $0.25 \mathrm{ml} / \mathrm{min}$ with either plasma electrolyte solution (PES) containing $\mathrm{Na} \mathrm{140,} \mathrm{K} 4 \mathrm{Cl} 104$, $\mathrm{HCO}_{3} 40 \mathrm{mmol} / \mathrm{l}$, and $4 \mu \mathrm{Ci} / 1$ of $\left[{ }^{14} \mathrm{C}\right]-\mathrm{PEG}$
4000 (non-challenged group), or else with the same solution to which $20 \mathrm{mg} / \mathrm{l}$ of ovalbumen was added (challenged group). Twenty minutes were allowed to elapse to reach steady state before five consecutive 10 minutes collections of the effluent were obtained from the distal cannula. Animals were maintained at $37^{\circ} \mathrm{C}$ using a heat pad and an overhead lamp. At the end of the experiments the rats were killed by an overdose of pentobarbitone and the perfused intestinal segment was removed, rinsed, blotted, and desiccated in an oven at $100^{\circ} \mathrm{C}$ to obtain dry weight. The samples of effluent were analysed immediately or kept frozen at $-20^{\circ} \mathrm{C}$ and analysed within two weeks.

\section{Drug administration}

At the time of anaesthetic administration, 90 minutes before intestinal perfusion, the animals were injected subcutaneously with either (a) ketanserin (200 $\mu \mathrm{g} / \mathrm{kg})$, (b) granisetron (300 $\mu \mathrm{g} / \mathrm{kg}$ ), (c) the same doses of ketanserin and granisetron in combination or (d) saline as control. In a further group of sensitised animals the mucosal mast cell stabiliser, doxantrazole in a dose of $30 \mathrm{mg} / \mathrm{kg}$ subcutaneously was given 30 minutes before perfusion.

\section{Analytical methods}

$\left[{ }^{14} \mathrm{C}\right]-\mathrm{PEG}$ concentrations in the effluent were measured in triplicate by liquid scintillation spectroscopy in KB Wallac Ultra-beta 1210 scintillation counter. Sodium and potassium concentrations were determined using flame photometer (Instrument Laboratories 943), and chloride concentrations by Chemlab (CCMI chloridmeter). The net water and solute movement was calculated and expressed respectively in $\mu \mathrm{g} / \mathrm{min} / \mathrm{g}$ and $\mu \mathrm{mol} / \mathrm{min} / \mathrm{g}$ of dry intestinal weight. Positive values denote net absorption and negative values net secretion.

\section{Materials}

Chicken egg albumen (grade V) was obtained from Sigma Chemical Company. The 5-HT antagonist ketanserin was supplied by Janssen, Belgium; and the 5- $\mathrm{HT}_{3}$ antagonist granisetron from SmithKline Beecham, UK. Doxantrazole was obtained from Wellcome, UK. Radiolabelled polyethylene glycol ( $\left.\left[{ }^{14} \mathrm{C}\right]-\mathrm{PEG} 4000\right)$ was obtained from Amersham International and all other chemicals were supplied by British Drug House (BDH Chemicals).

\section{Statistics}

Results are expressed as median and interquartile range and Wilcoxon rank sum test was used for statistical analysis.

\section{Results}

All rats developed a specific anti-ovalbumen IgE titre of $>1: 814$ days after initial inoculation of egg albumen and adjuvant. 

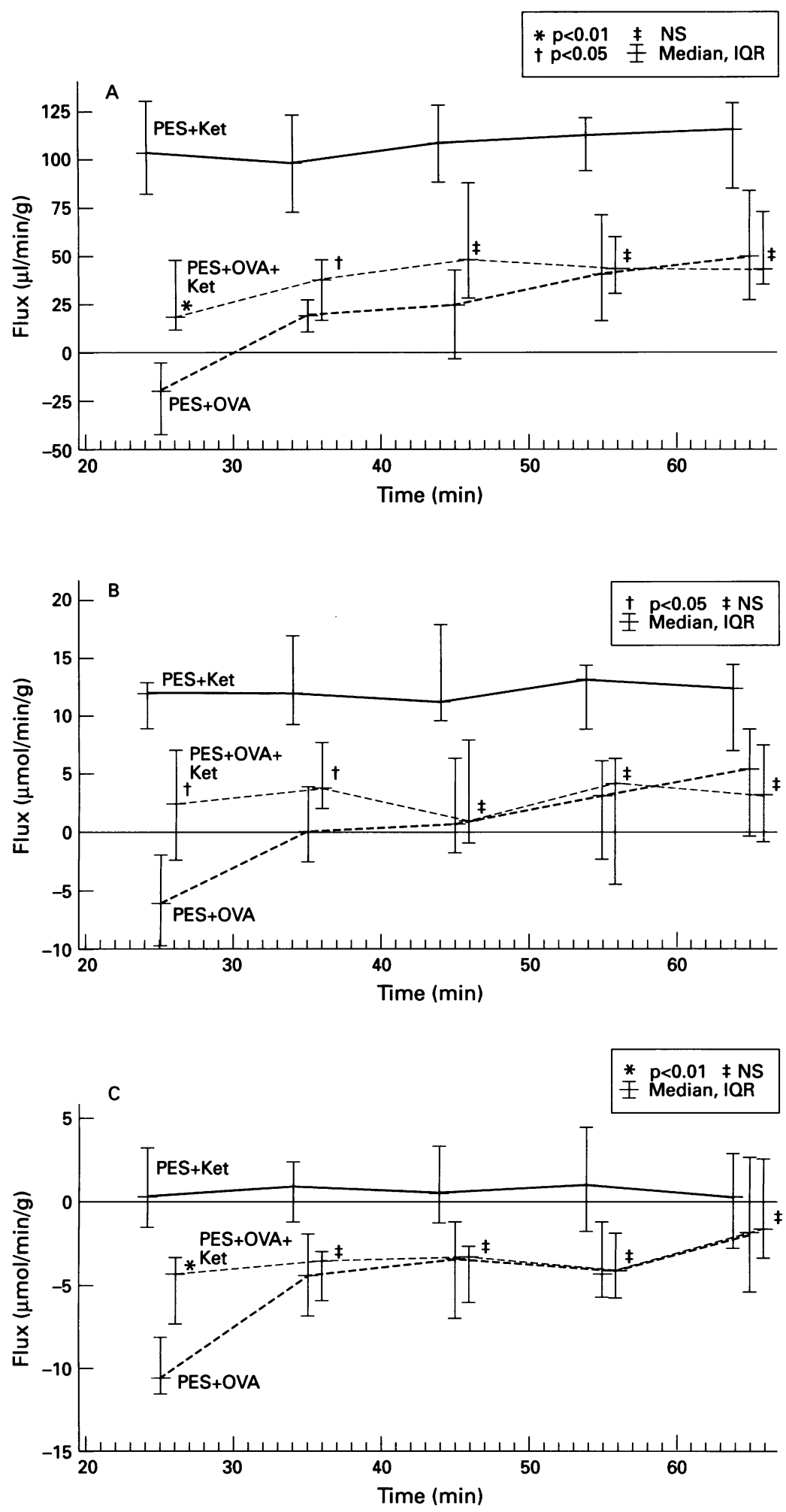

Figure 2: Effect of ketanserin on water $(A)$, sodium $(B)$, and chloride $(C)$ movement in control (PES + Ket, $n=10)$ and in challenged rats during gut anaphylaxis $(P E S+O V A+K e t, n=7)$. Time (min): time after the start of perfusion. All $p$ values compared with PES +OVA. the ovalbumen exposure, the secretory state ceased, but there was still a noticeable decrease in water absorption compared with controls perfused with PES alone. This reduction in water absorption persisted throughout the $\mathbf{7 0}$ minutes experimental period. Sodium and chloride movement parallelled that of water, with net sodium and chloride secretion occurring after 20 minutes of ovalbumen challenge (Figs 1B and 1C) with progressive recovery during 70 minutes of experimental period.

These changes in water and electrolyte movement were shown to be dependent on mast cell degranulation as they were completely abolished by the mast cell stabiliser, doxantrazole (Fig 1).

Neither ketanserin nor granisetron had any effect on water and electrolyte absorption in normal, non-challenged rats (Figs 1, 2, 3). In the challenged group, however, both ketanserin $(200 \mu \mathrm{g} / \mathrm{kg}$ ) and granisetron (300 $\mu \mathrm{g} / \mathrm{kg}$ ) reversed the water secretion seen at 20-30 minutes to absorption (ketanserin: 18 (11-48) $\mu \mathrm{l} / \mathrm{min} / \mathrm{g}, \mathrm{n}=7$; and granisetron: 13 (6-32); $\mathrm{n}=8$; both $\mathrm{p}<0.01$ compared with challenged animals) and significantly improved water absorption during the 30-40 minute period after challenge (Figs $2 \mathrm{~A}$ and $3 \mathrm{~A}$ ). During these two periods (20-30 and 30-40 minutes), water absorption was still significantly less than that in normal, non-challenged controls. After 40 minutes of challenge, $5-\mathrm{HT}_{2}$ and $5-\mathrm{HT}_{3}$ antagonism had no effect on water absorption, which still remained less than in normal controls. Sodium and chloride movement was similarly improved by prior treatment with ketanserin (Figs 2B and 2C) and granisetron (Figs 3B and 3C). Giving a combination of ketanserin and granisetron did not show any additive effect over each one alone in reversing water (Fig 4), sodium or chloride (data not shown) secretion.

\section{Discussion}

Our results show that a severe cholera like water secretion occurs within 20 minutes of exposure of sensitised intestine to allergen. This secretory phase is followed by a period of appreciable decrease in water absorption lasting for at least 30 minutes. The secretion during the early stage can be partially inhibited by $5-\mathrm{HT}_{2}$ and $5-\mathrm{HT}_{3}$ antagonists suggesting a role for 5-HT as a mediator during this stage. The decrease in water absorption occurring later in anaphylaxis is unlikely to be mediated by $5-\mathrm{HT}_{2}$ or $5-\mathrm{HT}_{3}$ receptors, as it is not affected by antagonists to these receptors. These changes in water movement during the entire period of intestinal anaphylaxis are dependent on mediators derived from mast cells as they were completely prevented by pretreatment with the mast cell stabilising agent, doxantrazole.

Perdue et $a l^{5}$ have shown in vivo that a decrease in water and electrolyte absorption but not net secretion occurs during exposure of presensitised intestine to ovalbumen and these findings have been confirmed in in vitro studies. $^{9-11}$ These changes in water and 

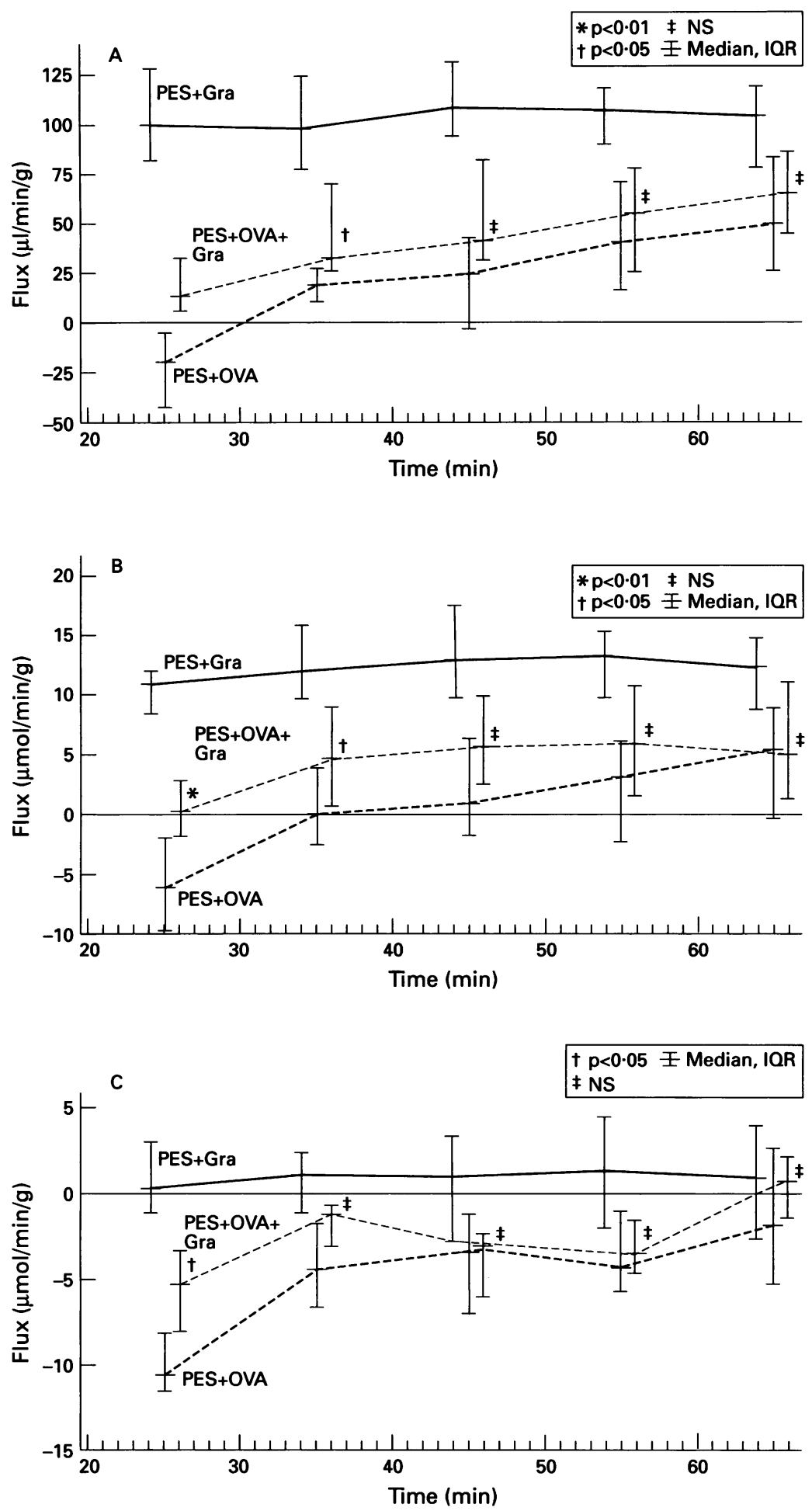

Figure 3: Effect of graniseton on water $(A)$, sodium $(B)$, and chloride $(C)$ movement in control (PES +Gra, $n=9)$ and in challenged rats during gut anaphylaxis (PES +OVA + Gra, $n=8)$. Time (min): time after the start of perfusion. All p values compared with $P E S+O V A$. could have been easily missed by less frequent collections.

The mediators responsible for the physiological changes during IgE mediated anaphylaxis still remain to be fully characterised. Histamine, being abundant in mast cells was thought to be an important mediator. In vitro studies using histamine antagonists have produced conflicting results, however, and failed to provide clear evidence that histamine acts as a secretagogue during gut anaphylaxis. ${ }^{7} 81113$ The effect of 5-HT and 5-HT antagonists have also been studied in vitro. Ketanserin and cinanserin (5- $\mathrm{HT}_{2}$ antagonists) were found respectively to decrease ${ }^{79}$ or abolish $^{8}$ the chloride response to antigen in sensitised gut. The 5- $\mathrm{HT}_{3}$ antagonist, ICS 205-930 also decreased chloride response to antigen in sensitised intestine to $\beta$ lactogloblulin. ${ }^{9}$ These experiments are the first to evaluate the effects of 5-HT receptor antagonists during anaphylaxis in vivo. It has previously been shown that 5-HT induces water secretion in rat jejunum when given intravenously, a process that can be attenuated or reversed by $5-\mathrm{HT}_{2}$ or $5-\mathrm{HT}_{3}$ receptor antagonists. ${ }^{14}$ Beubler et al ${ }^{15}$ showed a complete inhibition of 5-HT induced intestinal secretion by subcutaneous injection of ketanserin or granisetron in doses similar to those used in our study. Our data suggest that 5-HT plays a part early in the anaphylactic reaction but not in the later stages. A possible explanation would be that mast cell degranulation leads to release of performed mediators such as 5-HT stored in the secretory granules, which act early to promote the secretory process. In addition, mast cell degranulation leads to de novo generation of lipid metabolites from cell membranes, which results in synthesis of prostaglandins, leukotrienes, and platelet activating factor, which could also act as secretagogues in the late phase. ${ }^{16-19}$ This notion is supported by the in vitro finding of a biphasic rise and fall (phase I and II) in short circuit current during exposure of a sensitised intestine to antigen. ${ }^{811}$ Castro et al ${ }^{11}$ have found that the phase $I$ is mimicked by exogenous $5-\mathrm{HT}$ and blocked by $5-\mathrm{HT}$ receptor antagonists; and phase II is mimicked by exogenous prostaglandin $\mathrm{E}_{2}$ and blocked by an inhibitor of prostaglandin synthesis. In addition, Catto-Smith et $a l^{8}$ have found that indomethacin inhibited the phase I response by $56 \%$ and completely abolished phase II, implying that prostaglandins play a part in phase I but are more important in phase II. Our results are in accordance with their findings and the water secretion seen during the early phase of anaphylaxis could be mediated by a combination of 5-HT and other mediators like prostaglandins leading to changes in the activity of multiple ion transporters, only some of which are blocked by 5-HT receptor antagonism; whereas the late changes are not 5-HT dependent.

We have found that both ketanserin and granisetron have the same effect on water movement implying that 5-HT acts through both type 2 and type 3 receptors to produce its secretory action. The present experiments, the use of a higher antigen load in the perfusate compared with that used by Perdue et al ${ }^{5}$ or to collection of effluent at more frequent intervals; this permitted us to detect changes occurring over very short periods of time especially as the secretion was short lived and 


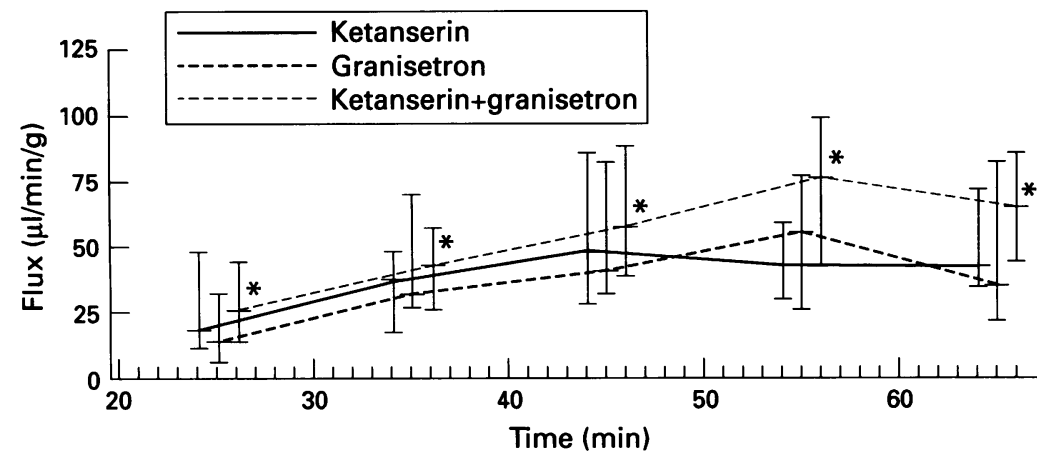

Figure 4: Effect of a combination of ketanserin and granisetron on water movement during gut anaphylaxis compared with either ketanserin $(n=7)$ or granisetron $(n=8)$ alone. Time (min): time after the start of perfusion. ${ }^{\star} N S$ compared with either ketanserin or granisetron alone. $\mathrm{I}$ median, IQR.

however, do not provide an explanation for the fact that a combination of ketanserin and granisetron at the doses used did not provide any additional benefit over each one alone.

In conclusion, our findings show that 5-HT plays a part in water movement changes during early phase of intestinal anaphylaxis in vivo as it is partially blocked by $5-\mathrm{HT}_{2}$ and $5-\mathrm{HT}_{3}$ antagonists, but it is highly likely that other mediators play a part in both the early and late phases of the anaphylactic reaction.

1 Kajosaari M. Food allergy in Finnish children aged 1 to 6 years. Acta Pediatr Scand 1982; 71: 815-9

2 Lessof MH, Wraith DG, Merret TG, Merret J, Buissere PD. Food allergy and intolerance in 100 patients - local systemic effects. $Q \mathcal{F}$ Med 1980; 195: 259-71.

3 Allen DH, van Nunen S, Loblay R, Clarke L, Swain A Adverse reactions to foods. Med $\mathcal{f}$ Aust 1984; 141 (supp 5): $\$ 37-42$.

4 Patrick MK, Dunn IJ, Buret A, Miller HRP, Huntley JF, Gibson S, et al. Mast cell protease release and mucosa ultrastructure during intestinal anaphylaxis in the rat. Gastroenterology 1988; 94: 1-9.

5 Perdue MH, Chung M, Gall DG. Effect of intestinal anaphylaxis on gut function in the rat. Gastroenterology 1984; phylaxis on $391-7$.

6 Jaffe BM, Ferrara A, Sherlock DJ. Comparative effects of ketanserin, atropine and methysergide on the gastrointestinal effects of hyperserotoninemia in the awake dog J Pharmacol Exp Ther 1986; 238: 536-41.

7 Crowe SC, Sestini P, Perdue MH. Allergic reaction of rat jejunal mucosa. Ion transport responses to luminal antigen and inflammatory mediators. Gastroenterology 1990 99: 74-82.

8 Catto-Smith AG, Patrick MK, Hardin JA, Gall DG. Intestinal anaphylaxis in the rat; mediators responsible for the ion transport abnormalities. Agents and Actions 1988; 28: $186-91$.

9 Baird AW, Cuthbert AW. Neuronal involvement in type 1 hypersensitivity reaction in gut epithelia. $\mathrm{Br} \mathcal{F}$ Pharmaco 1987; 92: 647-55.

10 Perdue MH, Gall DG. Intestinal anaphylaxis in the rat, jejunal response to in vitro challenge. Am $\Im$ Physiol 1986; 250 G427-31.

11 Castro GA, Harari Y, Russell D. Mediators of anaphylaxisinduced ion transport changes in small intestine. $A m \mathcal{F}$ Physiol 1987; 253: G540-8.

12 Miller HRF, Woodbury RG, Huntley JK, Newlands G. Systemic release of mucosal mast cell protease in primed rats challenged with Nippostrongylus brasiliensis. rats challenged with 1983 ; 49: 471-9.

13 Perdue MH, Gall DG. Rat jejunal mucosa responses to histamine and antihistamines in vitro. Comparison with antitamine and antihistamines in vitro. Comparison with antigen-induced changes dur
Actions 1986; 19: 5-9.

14 Beubler E, Horina G. 5- $\mathrm{HT}_{2}$ and $5-\mathrm{HT}_{3}$ receptor subtypes mediate cholera toxin-induced intestinal $\mathrm{f}$ secretion in the rat. Gastroenterology 1990; 99: 83-9.

15 Beubler E, Shirgi-Degen A, Gamse R. Inhibition of 5 hydroxytryptamine and enterotoxin-induced fluid secretion by 5 -HT receptor antagonists in the rat jejunum. Eur f Pharmacol 1993; 248: 157-62.

16 Serafin WE, Austen KF. Mediators of immediate hypersensitivity reactions. $N$ Engl $\mathcal{F}$ Med 1987; 317: $30-4$.

17 Barret KE, Metcalfe DD. Mucosal mast cells and IgE. In: Heyworth MF, Jones AL, ed. Immunology of the gastrointest

18 Donowitz M, Welsh MJ. Regulation of mammalian smal intestinal electrolyte secretion. In: Johnson LR, ed. Physiology of the gastrointestinal tract. New York: Raven, 1987: 1351-88.

19 Hanglow AC, Bienenstock J, Perdue MJ. Effect of plateletactivating factor on ion transport in isolated rat jejunum. Am f Physiol 1989; 257: G845-50. 